\title{
Casa de Vidro de Lina Bo Bardi: avaliação da estrutura
}

\author{
RICARDO COUCEIRO BENTO - PROFESSOR DOUTOR \\ Departamento de Arquitetura e Urbanismo, Pontificia \\ Universidade Católica de Minas Gerais - PUC MINAS
}

\author{
JOÃO ADRIANO ROSSIGNOLO - ProfESSOR DoUTOR \\ Departamento de Engenharia de Biossistemas, \\ Universidade de São PaUlo - ZEB/FZEA
}

\section{RESUMO}

A Casa de Vidro, construída em 1951 em São Paulo, considerada UM ÍCONE DA ARQUITETURA MODERNA BRASILEIRA, PROJETADA PELA ARQUITETA ÍTALO-BRASILEIRA LINA BO BARDI, RECEBEU, EM 2016, O APOIO PARA REALIZAR UM PLANO DE MANUTENÇÃO PREVENTIVA BASEADO EM PESQUISAS TÉCNICAS DA FUNDAÇÃO GETTY, INSTITUIÇÃO NORTE-AMERICANA POR MEIO do programa KeEeing it Modern. Os fundos da Fundação Getty PERMITIRAM QUE UMA EQUIPE INTERNACIONAL DE ESPECIALISTAS EM CONSERVAÇÃO DE ARQUITETURA E PAISAGISMO, ESPECIALISTAS EM PATRIMÔNIO
E ENGENHEIROS CIVIS DESENVOLVESSEM UM PLANO DE GESTÃO DE CONSERVAÇÃO PARA A OBRA.

ESTE ARTIGO REFERE-SE AO ITEM DO PROJETO CUJA EQUIPE DE TRABALHO EFETUOU A VERIFICAÇÃO DOS COMPONENTES ESTRUTURAIS QUANTO À CAPACIDADE RESISTENTE DO PONTO DE VISTA DE SEGURANÇA E DURABILIDADE, EM CONSEQUÊNCIA DA ALTERAÇÃO DE USO DURANTE A VIDA ÚTIL DA EDIFICAÇÃO, ORIGINALMENTE PROJETADA COMO RESIDENCIAL PARA ATUALMENTE SER UM ESPAÇO DE VISITAÇÃO PÚBLICA.

Palavras-chave: análise estrutural, vida útil, Lina Bo Bardi, Casa de Vidro, patrimônio modernista.

\section{INTRODUÇÃO}

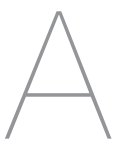

Casa de Vidro, como é hoje conhecida a sede do Instituto Bardi, em São Paulo, é um ícone da Arquitetura Moderna. O edifício serviu, por quatro décadas, como residência do casal formado pela arquiteta Lina Bo Bardi (1914-1992) e pelo crítico, comerciante de arte e diretor do Museu de Arte de São Paulo - Masp, Pietro Maria Bardi (1900-1999), italianos de origem e naturalizados brasileiros. Com projeto iniciado em 1949 e construção finalizada em 1952, a casa reflete ideais formais, técnicos e de vida propalados pela Arquitetura Moderna. Uma foto da fachada na época está ilustrada na figura 1.

O projeto de preservação de patrimônio histórico, sob a coordenação geral do prof. Dr. Renato Anelli, recebeu o apoio da Fundação Getty, instituição norte-americana, por meio

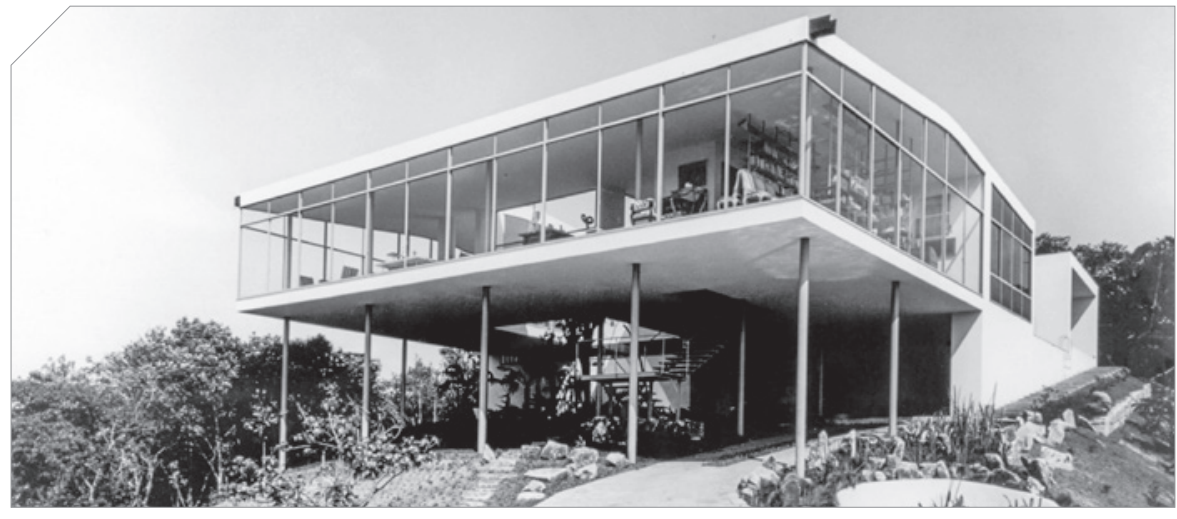

Figura I - Foto da fachada da Casa de Vidro em meados de 1952 Fonte: Instituto Moreira Salles

do programa Keeping it Modern, que apoia a realização de planos de gestão e manutenção dos bens históricos (ANELLI et al, 2019).

Ao participar do programa, o Instituto Bardi, em convênio com um grupo de pesquisadores do Instituto de Arquitetura e Urbanismo - IAU da Universidade de São Paulo - USP, propôs combinar quatro frentes de pesquisa, denominadas como
"Tarefas" descritas suscintamente a seguir:

- Tarefa 1: Sistematizar o estudo documental da história da casa;

- Tarefa 2: Realizar levantamentos digitais cuidadosos da arquitetura da construção principal, anexos e jardim;

- Tarefa 3: Identificar a situação de conservação dos sistemas construtivos, em especial sua estrutura; 
- Tarefa 4: Avaliar a situação do jardim, entendido como elemento fundamental da concepção.

Este artigo apresenta um resumo do estudo efetuado na Tarefa 3 do plano de trabalho do projeto, relativo a estrutura de concreto armado, cujos autores deste artigo foram responsáveis: a avaliação da capacidade estrutural atual considerando a mudança do uso da construção, a fim de minimizar sua deterioração.

\section{PLANO DE ESTUDO}

Para a análise da estrutura visando os seguintes procedimentos foram efetuados: estudo e interpretação das informações do projeto estrutural original, verificações in $10 c 0$ dos componentes estruturais, análise do projeto da estrutura original em programas de cálculo estrutural.

\section{I Estudo $\in$ interpretações das informações do projeto estrutural original}

Para "suspender" a Casa de Vidro, a arquiteta decidira pelo emprego de tubos Mannesman, tubos de aço sem costura produzidos pela empresa alemã. Segundo seus relatos, também usaria tubos de fibrocimento no primeiro pavimento. Essa escolha dos tubos metálicos provavelmente refletia a admiração de Lina por obras do arquiteto Mies van der Rohe e outros.

Inicialmente foi solicitado ao notório engenheiro italiano Pier Luigi Nervi (1871-1979) o projeto e cálculo estrutural. Para seu projeto, Nervi indicava o uso de tubos Mannesman de diâmetro externo não menor que $17 \mathrm{~cm}$, preenchidos de concreto de ótima qualidade. Conforme prometido a Nervi, Lina e Pietro contrataram uma empresa organizada para a construção da casa: a Sociedade Comercial Construtora S.A., então uma das mais importantes da cidade e responsável por grandes obras em concreto armado.

Quando foi contratada, a Construtora deveria executar apenas a estrutura e muros de arrimo da Casa, sob regime de administração. $\mathrm{Na}$ proposta de serviços, a empresa afirmava que havia usado cálculos próprios para o projeto estrutural, dadas as dificuldades de aquisição de vigas laminadas especiais conforme o projeto de Nervi. O autor do novo projeto estrutural foi o engenheiro Tullio Stucchi, nascido no interior de São Paulo em 1914, formado pela Escola Politécnica da USP, em 1937. Desde 1944, trabalhava como engenheiro calculista de concreto armado na Sociedade Comercial Construtora. Executados em 1951, os projetos estruturais de Nervi e Stucchi revelam que parte da melhor engenharia de concreto do período, na Itália e no Brasil, foi mobilizada e fez-se os melhores esforços para viabilizar a particular estética moderna prevista pela arquiteta.

Do estudo das pranchas disponíveis (que se encontram disponíveis no Instituto Bardi), se observou que, apesar do bom nível de detalhamento, não foram identificadas algumas informações de extrema importância ao trabalho, como a especificações do concreto, o tipo de aço utilizado na estrutura e o detalhamento dos pilares construídos com tubos de aço (este detalhamento perdido). Devido a essa dificuldade foram então

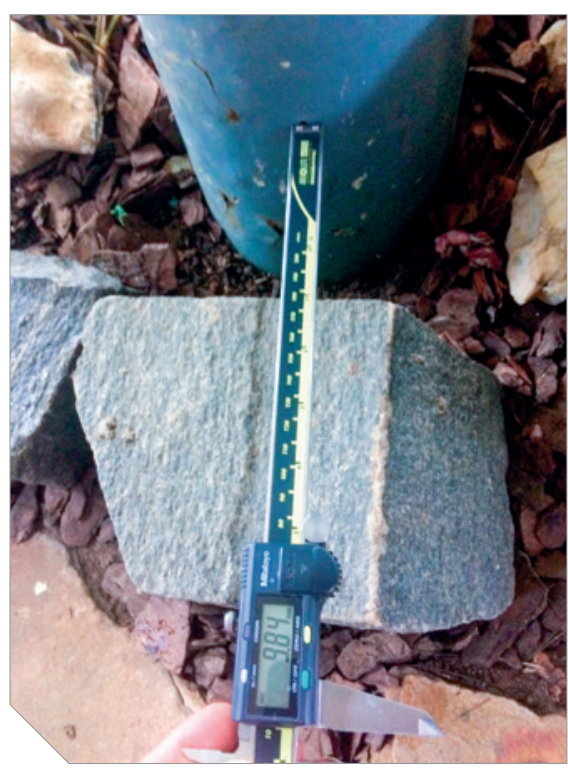

Figura 2 - Medição da espessura do tubo de aço

Fonte: Autor

efetuadas investigações complementares para a viabilização da análise estrutural da residência.

\subsection{Verificação in loco dos componentes estruturais}

Foi efetuada a medição das dimensões das peças estruturais acessíveis e mais importantes. A figura 2 ilustra a medição no furo efetuado em uma coluna cilíndrica para a verificação da espessura do tubo de aço Mannesman e da existência de concreto em seu interior. Foi também executada prospecção por ultrassonografia pela Prof. ${ }^{a}$ Dr $^{a}$ Raquel Gonçalves (UNICAMP), para a confirmação da existência do concreto dentro do tubo de metal (figura 3). Ainda quanto às sapatas dos pilares em tubos de aço cilíndricos, foi feita uma amostragem com a abertura de cavas para a verificação da profundidade das mesmas (figura 4). Quanto à espessura das lajes do pavimento superior, por meio de medição pelas 


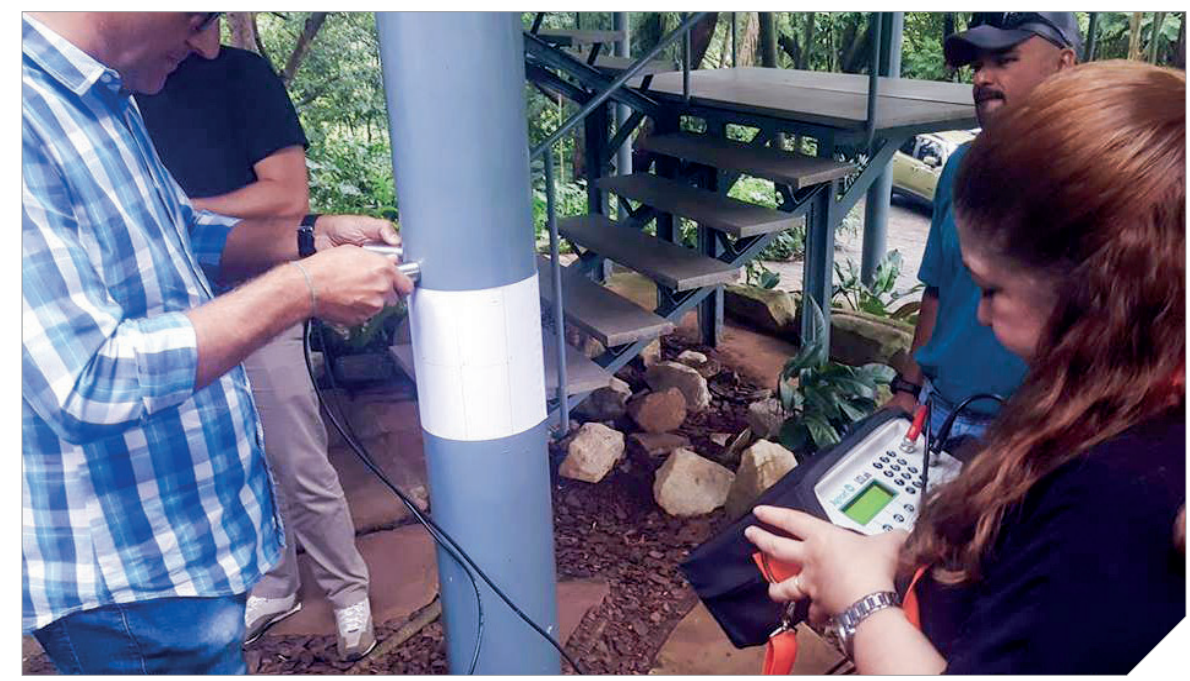

Figura 3 - Execução de ultrassonografia nos pilares Fonte: Autor

tomadas do piso do $1^{\circ}$ pavimento foi confirmada a espessura de projeto, conforme figura 5 .

Complementarmente, uma investigação visual foi realizada com a

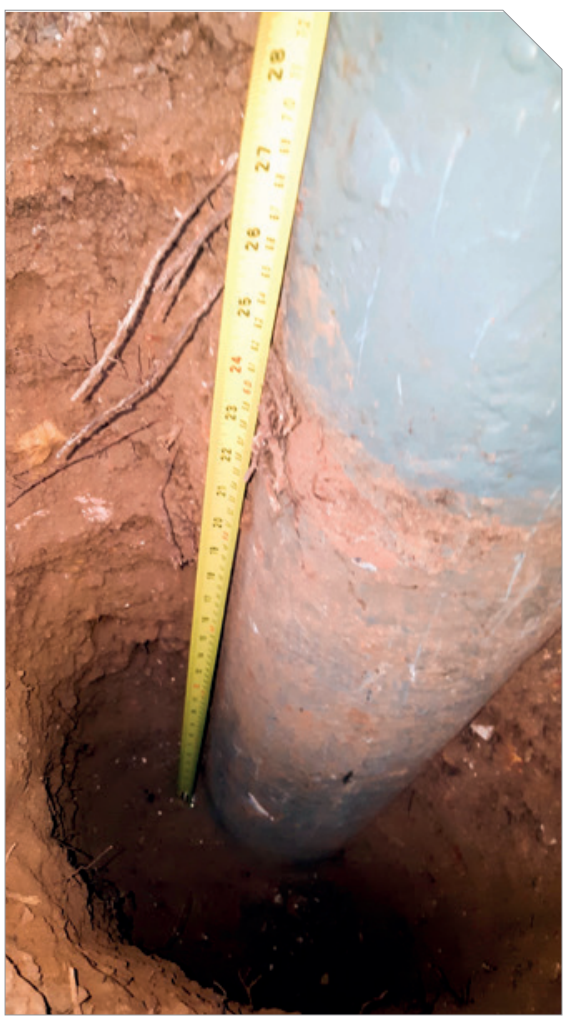

figura 4 - Abertura de cavas nos pilares para a verificação da profundidade das sapatas Fonte: Autor observação de manifestações patológicas que pudessem denunciar algum dano ou desgaste excessivo da estrutura, não tendo sido verificada qualquer ocorrência significativa.

Quanto às especificações técnicas do concreto, não foi encontrado nenhum dado a seu respeito que viabilizasse a execução de uma projeção de resistência com o passar dos anos, necessária para a avaliação estrutural. O fato deste dado de suma importância para a análise da estrutura ser desconhecido resultou na necessária investigação direta, que foi efetuada por meio da contratação do Centro Tecnológico de Controle da Qualidade Falcão Bauer.

Devido à importância na preservação estética e objetivando uma investigação com um mínimo de intervenção, foi executada a extração de testemunhos com o diâmetro de $27 \mathrm{~mm}$, chamados minitestemunhos, em substituição aos testemunhos usuais de diâmetros de $100 \mathrm{~mm}$ ou $75 \mathrm{~mm}$. A utilização dos resultados da resistência à compressão do condos minitestemunhos na avaliação creto em estruturas acabadas foi adotada com base em correlações estatísticas, em consonância com os estudos de VIEIRA FILHO (2007). Uma imagem da extração de um minitestemunho pode ser verificado na figura 6 .

Foi complementarmente efetuado o ensaio para verificação da profundidade de carbonatação na estrutura de concreto. Uma imagem do ensaio no minitestemunho extraído, com o uso do indicador de fenolftaleína pode ser verificado na figura 7 .

Posteriormente, pesquisadores da "Tarefa 1" localizaram detalhes na Itália, de autoria de Nervi, com especificações quanto às características mínimas dos pilares, espessuras dos tubos, ligações com as lajes e fundações, bem como o consumo mínimo de cimento $\left(400 \mathrm{~kg} / \mathrm{m}^{3}\right)$. Nos detalhes encontrados também foi fornecida uma carga máxima para as fundações, 45 toneladas, e admitida a capacidade de carga máxima do solo para uma tensão de 0,15MPa.



Figura 5 - Verificação da espessura da laje pela tomada do lo pavimento Fonte: Autor 
2.2.I Avaliação da ReSISTÊnCIA DO CONCRETO PARA FINS DE VERIFICAÇÃO DA SEGURANÇA ESTRUTURAL

Foi efetuada a análise estatística assistemática, que engloba toda a estrutura em um único lote, dado o pequeno número de testemunhos que foram permitidos serem extraídos da edificação.

A ABNT NBR 7680-1:2015 e a ABNT NBR 6118:2014 foram o guia de orientação para a avaliação da resistência do concreto a ser usada na verificação da segurança estrutural e da estabilidade global. Foi considerado que ambas as ações, efeito Rüsch e crescimento da resistência, estão estabilizadas aos 50 anos.

O resultado obtido foi a resistência do concreto de 32,92 MPa. Posteriormente foi adotado um dos valores de classe concreto estabelecidos pela ABNT NBR 8953:2015, sendo admitida a classe do concreto de 30 MPa para a avaliação.

\section{2.己.己 AvaliaÇÃO DA PROFUndidAdE de CARBONATAÇÃO PARA FINS DE VERIFICAÇÃO DA SEGURANÇA ESTRUTURAL}

O cobrimento da estrutura é de $20 \mathrm{~mm}$ e o revestimento de $15 \mathrm{~mm}$, ambos confirmados in loco. A profundidade de carbonatação encontrada tem um valor máximo de $10 \mathrm{~mm}$. Diante dos resultados obtidos, conclui-se que a camada passivadora das barras encontra-se preservada.

\subsubsection{CONSIDERAÇÃO DAS CARACTERÍSTICAS DOS VERGALHÕES DE AÇO UTIUIZADOS NA ESTRUTURA}

Devido à impossibilidade da retirada de amostras dos vergalhões da

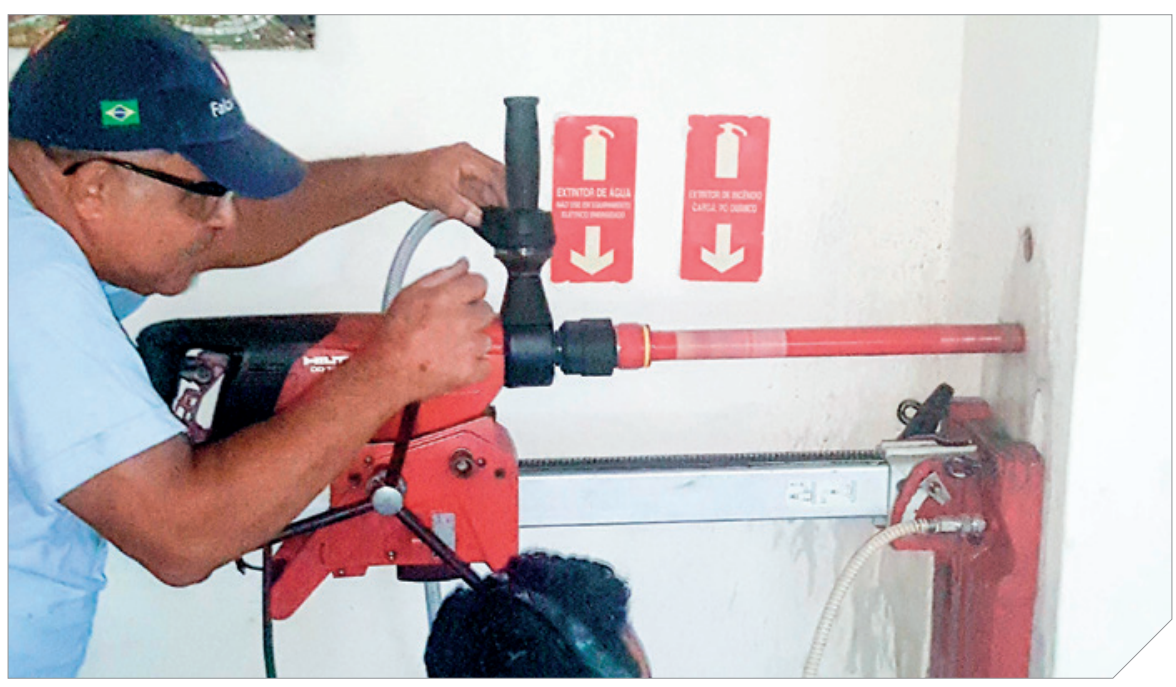

Figura 6 - Extração de minitestemunhos Fonte: Autor

estrutura da residência, foram admitidas suas características segundo a versão da EB3-1939, naquela época definindo apenas os aços 37CA e 50CA, com limite de escoamento de 24 a $30 \mathrm{Kgf} / \mathrm{mm}^{2}$, equivalentes a 240 e $300 \mathrm{MPa}$, respectivamente (STUCCHI, 2018)

\subsection{Análise do projeto da estrutura em software de projetos estruturais}

De posse das informações des- critas nos itens anteriores, foi efetuada a análise dos dados do projeto da estrutura original em programas de projeto estrutural.

Os softwares utilizados foram o Sistema TQS para Engenharia de Estruturas para a determinação dos esforços e verificação dos detalhes da estrutura de concreto armado.

Para a análise exclusiva dos pilares redondos mistos em aço e concreto, foi utilizado, sob a orientação do engenheiro Flávio Gaiga (professor-

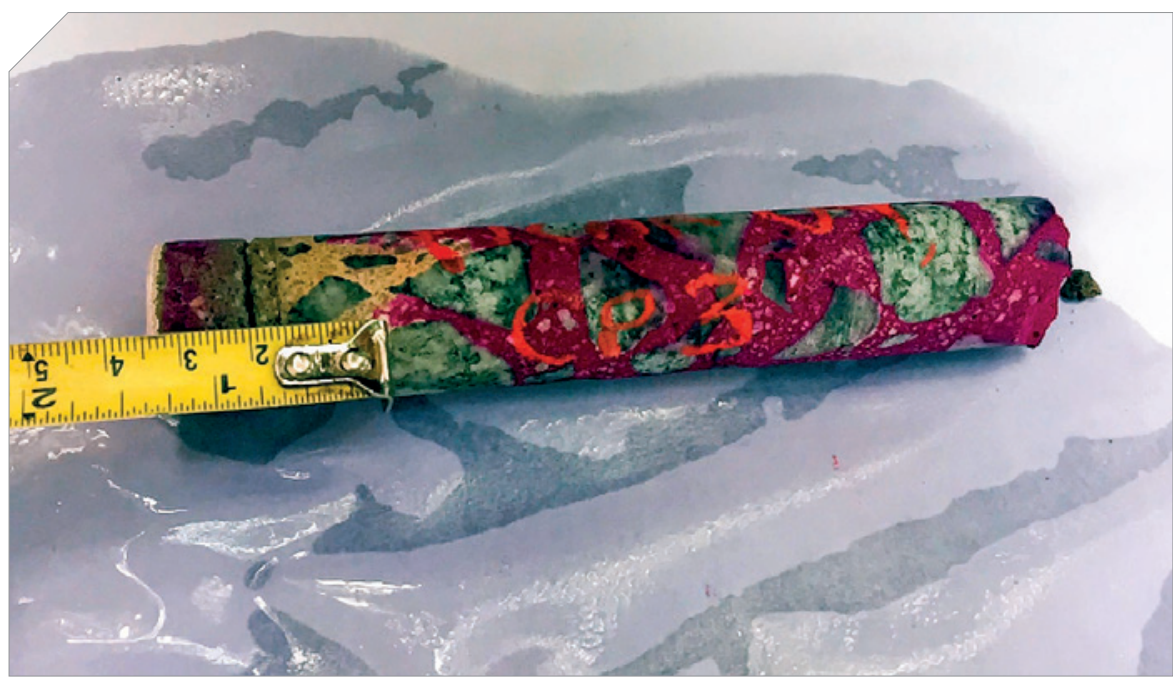

Figura 7 - Ensaio para verificação da profundidade de carbonatação Fonte: Autor 


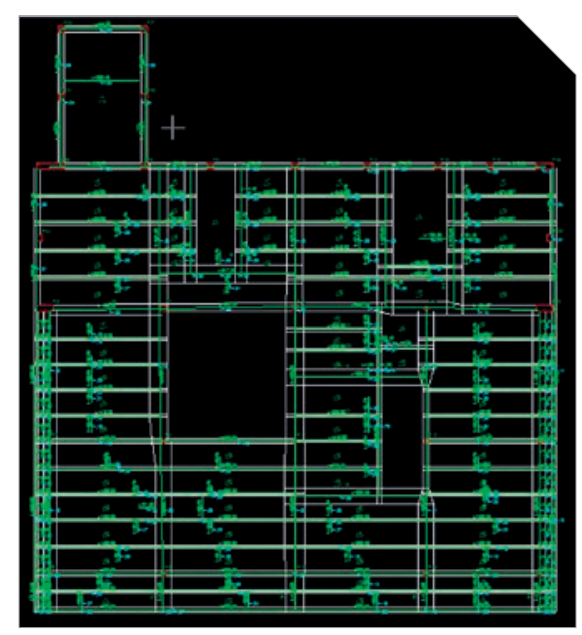

Figura 8 - Modelagem do pavimento superior $\in$ projeto original Fonte: Autor

mestre na PUC-MINAS), o software Pilar Misto V\&M-UFMG - Programa Pilar Misto, o qual verifica os pilares tubulares de aço preenchidos com concreto. Este programa foi desenvolvido pela Universidade Federal de Minas Gerais - UFMG.

Na análise estrutural, foi necessária a consideração do uso atual da edificação, não mais como originalmente concebida como uma residência, mas com o uso atual que foi classificado como um pequeno museu ou uma galeria de arte na consideração das sobrecargas acidentais.

Pode ser verificada, na figura 8 , a modelagem atual deste pavimento.

$\mathrm{Na}$ figura 9, é apresentada uma

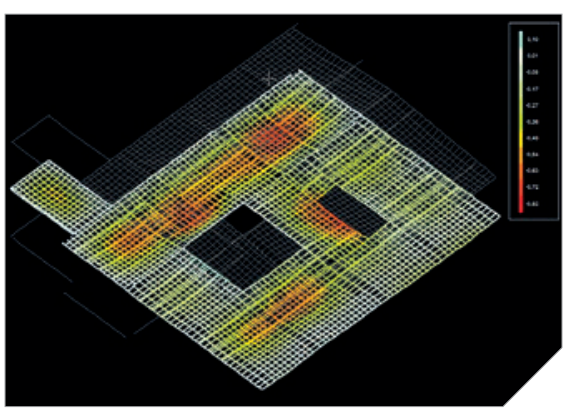

Figura 9 - Imagem dos resultados de grelha não linear do pavimento superior

Fonte: Autor imagem da análise de grelha não linear do pavimento superior e, na figura 10, uma imagem 3D de uma das modelagens estruturais testadas e avaliadas.

Na figura 11, é apresentada uma foto da icônica edificação nos dias atuais.

\subsection{ANÁLISE DAS FUNDAÇ̃̃ES SUPERFICIAIS EM SAPATAS ISOLADAS}

Por meio dos resultados obtidos na modelagem estrutural aplicados às dimensões das fundações, verificou-se uma transferência de tensões médias ao solo da ordem de 0,076MPa, variando de um mínimo de 0,039Mpa a um máximo de 0,114MPa. No caso específico das fundações dos pilares mistos de aço-concreto que dão suporte à laje do piso do pavimento superior, a tensão média transferida ao solo foi de 0,089 Mpa, variando de um mínimo de 0,08Mpa a um máximo de 0,114MPa. Conforme já citado, o detalhe do projeto de Nervi indica a consideração de uma capacidade de carga do solo para uma tensão de $0,15 \mathrm{Mpa}$, o que talvez sugira a troca de informações entre o projetista brasileiro e o italiano na época da concepção do projeto estrutural, mas é apenas uma suposição.

\subsubsection{Análise dos pilares}

\subsubsection{PILARES MISTOS DE AÇO-CONCRETO TUBULARES}

Os pilares mistos aço-concreto tubulares foram avaliados para as solicitações obtidas na modelagem estrutural com a medida das dimensões mensuradas in loco.

Não foi considerado em nenhum caso, para a análise dos pilares mistos aço-concreto tubulares, a contribuição de armadura interna, apenas o preenchimento de concreto. A existência de armaduras na massa de concreto não foi encontrada nos detalhes dos projetos (apenas nos

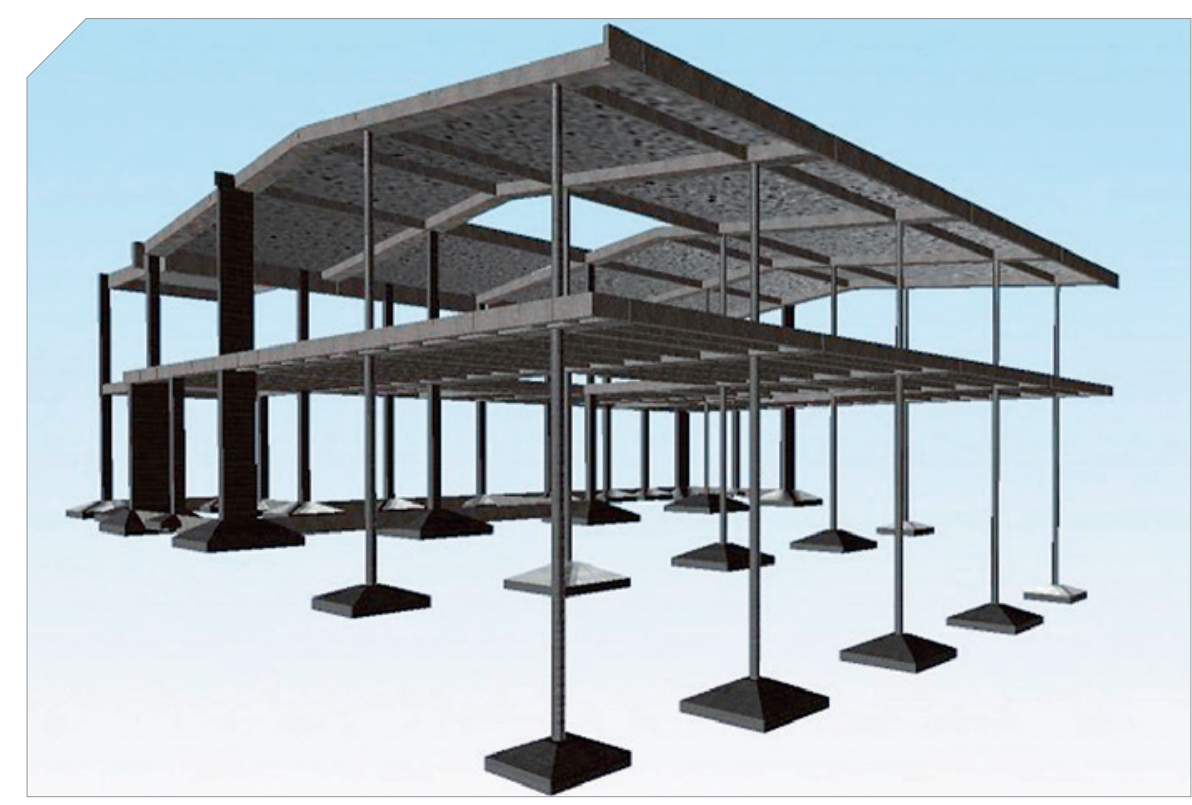

Figura IO - Imagem 3D de uma das modelagens estruturais testadas $\epsilon$ avaliadas Fonte: Autor 


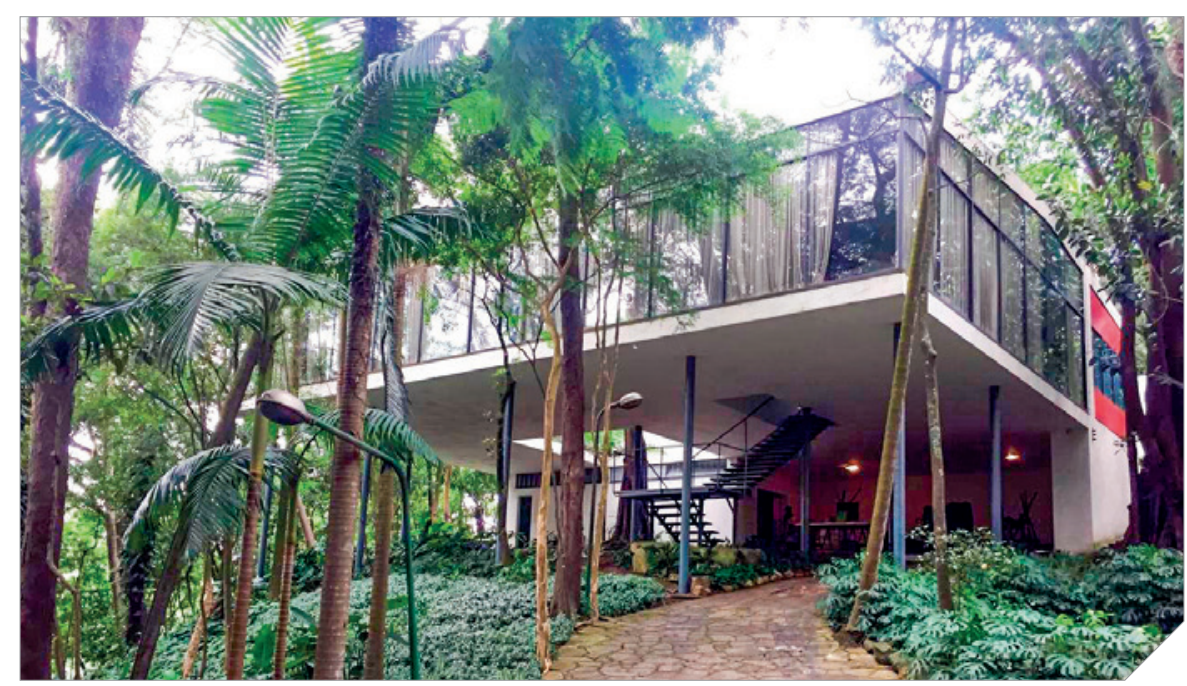

Figura II - Fachada da Casa de Vidro atualmente

Fonte: Autor

detalhes dos arranques das fundações) e não foi detectada por meio dos ensaios de ultrassonografia executados. Consequentemente, dada a incerteza, optou-se pela não consideração da sua existência nas análises.

Os pilares foram avaliados por dois modelos de cálculo, o modelo de cálculo I (modelo que segue por base a norma americana ANSI/AISC 360-05 - Specification for Structural Steel Buildings), e o modelo de cálculo II (uma verificação que tem por base o método simplificado da norma européia EN 1994-1-1:2004: Design of composite steel and concrete structures - Part 1-1: General rules and rules for buildings).

A avaliação dos pilares mistos aço-concreto tubulares existentes, submetidos às solicitações obtidas na modelagem estrutural, obteve resultados que confirmaram a segurança estrutural destas peças quanto ao uso pretendido.

\subsubsection{PILARES EM CONCRETO ARMADO}

O projeto estrutural original, no que diz respeito ao detalhamento dos pilares, apenas especifica a armadura dos arranques dos mesmos. Para a verificação das armaduras internas dos pilares, a única referência utilizada foi essa informação, com a dedução de continuidade das armaduras aos pavimentos superiores.

Por meio da avaliação dos resultados da modelagem estrutural dos pilares em concreto armado, os pilares de suporte da laje do piso do pavimento superior, quanto às suas dimensões e esbeltez, encontram-se todos em conformidade. Quanto aos pilares que suportam a cobertura, conforme esperado, alguns apresentam dimensões inferiores às prescri-

\subsubsection{Análise dAS LaJes E VIGAS}

A estrutura dos pavimentos foi modelada com as dimensões do projeto original e as deformações foram avaliadas por meio do processo de grelha não linear. Quanto às deformações da ções mínimas atuais. DO PAVIMENTO SUPERIOR E COBERTURA estrutura, elas se encontram dentro dos parâmetros de norma, tanto para a laje como as vigas, demonstrando-se adequado ao uso pretendido.

\subsubsection{Avaliação dos deslocamentos DO PÓRTICO ESPACIAL}

O parâmetro de estabilidade global obtido foi de um valor alfa de 0,65 (valor de referência 0,6). Os deslocamentos horizontais resultaram em um valor máximo de $0,27 \mathrm{~cm}$ no topo do edifício (valor de referência de $0,56 \mathrm{~cm}$ ) e um deslocamento entre pisos de $0,15 \mathrm{~cm}$ (valor de referência de $0,37 \mathrm{~cm}$ ). Os deslocamentos encontram-se dentro de limites considerados aceitáveis.

\section{CONCLUSÕES}

Por meio dos estudos executados, as conclusões são as seguintes: a estrutura se encontra com estado de conservação satisfatório, dada a idade da construção. O processo de carbonatação não atingiu as armaduras no interior da estrutura.

Quanto ao Estado Limite Último (ELU), por meio da comparação entre a análise atual e o projeto estrutural original, com os detalhes e as hipóteses adotadas na avaliação, a estrutura foi considerada segura. Quanto ao detaIhamento das armaduras, verificou-se, como esperado, algumas variações, as quais não foram consideradas significativas a ponto de resultar em uma não aprovação da estrutura. No que diz respeito às fundações para o uso pretendido, estas se encontram seguras quanto às solicitações.

A avaliação dos pilares mistos aço-concreto tubulares existentes 
submetidos às solicitações obtidas na modelagem estrutural obteve resultados que confirmaram a segurança estrutural. Os pilares de suporte da laje do piso do pavimento superior quanto às suas dimensões e esbeltez também se encontram em conformidade.

Quanto ao Estado Limite de Servi- ço (ELS), foram encontrados valores de deslocamentos da estrutura e deformações das vigas e lajes dentro dos limites da normatização atual.

\section{AGRADECIMENTOS}

Nossos agradecimentos ao Instituto Bardi/Casa de Vidro, pelo apoio e colocação à disposição de seu acervo, ao Instituto de Arquitetura e Urbanismo - IAU da Universidade de São Paulo, pela organização, à Fundação Getty, pelo financiamento do projeto e aos profissionais participantes que colaboraram direta ou indiretamente com os trabalhos.

\section{REFERÊNCIAS BIBLIOGRÁFICAS}

[1] ANELLI, R. (organizador); SUZUKI, M. (supervisor); Casa de Vidro: Arquiteta Lina Bo Bardi: plano de gestão e conservação, São Paulo, Instituto Bardi Casa de Vidro, 2019, 475p.

[2] AMERICAN NATIONAL STANDARDS INSTITUTE. ANSI/AISC 360:05 - Specification for Steel Structural Buildings. Washington, 2005.

[3] ASSOCIAÇÃO BRASILEIRA DE NORMAS TÉCNICAS (ABNT). ABNT NBR 6118 Projeto de estruturas de concreto - Procedimento Rio de Janeiro,2014, 238 p.

[4] ASSOCIAÇÃO BRASILEIRA DE NORMAS TÉCNICAS (ABNT). ABNT NBR 7680-1 Concreto - Extração, preparo, ensaio e análise de testemunhos de estruturas de concreto Parte 1: Resistência à compressão axial. Rio de Janeiro, 2015, 24 p.

[5] EN 1994-1-1 (2004) (English): Eurocode 4: Design of composite steel and concrete structures - Part 1-1: General rules and rules for buildings [Authority: The European Union Per Regulation 305/2011, Directive 98/34/EC, Directive 2004/18/EC].

[6] STUCCHI, F.R.; Os vergalhões e o concreto armado no Brasil. Concreto \& Construções, Edição 92, IBRACON, São Paulo, 2018.

[7] VIEIRA FILHO, J. O.; Avaliação da resistência à compressão do concreto através de testemunhos extraídos: contribuição à estimativa do coeficiente de correção devido aos efeitos do broqueamento. São Paulo. Escola Politécnica da USP, PPEGEC, julho, 2007 (Tese de doutorado).

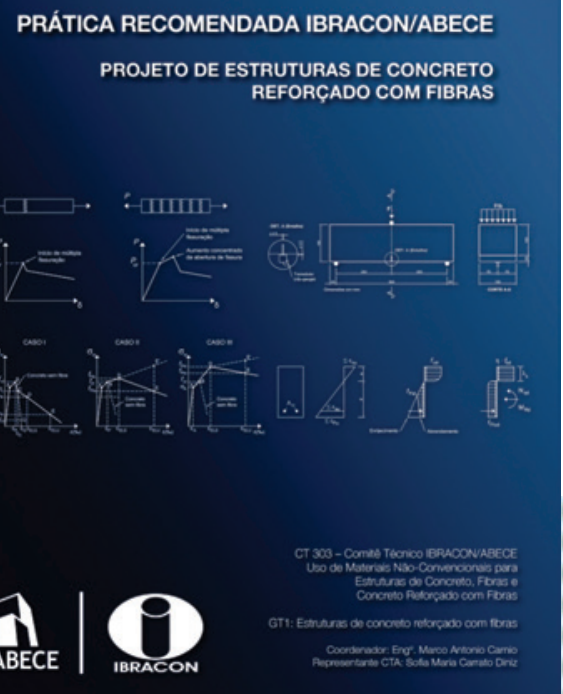

Elaborada pelo CT 303 - Comitê Técnico IBRACON/ABECE sobre Uso de Materiais Não Convencionais para Estruturas de Concreto, Fibras e Concreto Reforçado com Fibras, a Prática Recomendada é um trabalho pioneiro no Brasil, que traz as diretrizes para o desenvolvimento do projeto de estruturas de concreto reforçado com fibras.

Baseada no fib Mode Code 2010, a Prática Recomendada estabelece os requisitos mínimos de desempenho mecânico do CRF para substituição parcial ou total das armaduras convencionais nos elementos estruturais e indica os ensaios para a avaliação do comportamento mecânico do CRF.

\section{Aquisição}

www.ibracon.org.br (loja virtual)

\section{DADOS TÉENICOS}

ISBN: 978-85-98576-26-8

Edição: $1^{a}$ edição

Formato: Eletrônico

Páginas: 39

Acabamento: Digital

Ano da publicação: 2016

Coordenador: Eng. Marco Antonio Carnio 